\title{
Role of Psychosocial Factors on Treatment Outcome of Temporomandibular Disorders
}

Jussi Huttunen $^{\mathrm{a}, \mathrm{b}}$, Veera Qvintus ${ }^{\mathrm{a}}$, Anna Liisa Suominen ${ }^{\mathrm{a}, \mathrm{c}}$, Kirsi Sipiläa,de*

${ }^{a}$ Institute of Dentistry, University of Eastern Finland, Kuopio, Finland

${ }^{\mathrm{b}}$ City of Ä̈̈nekoski, Public Health Center, Oral Health Care Services, Ä̈̈nekoski, Finland

${ }^{\mathrm{c}}$ Oral and Maxillofacial Department, Kuopio University Hospital, Kuopio, Finland

${ }^{\mathrm{d}}$ Research Unit of Oral Health Sciences, University of Oulu, Oulu, Finland

e Oral and Maxillofacial Department, Medical Research Center Oulu, Oulu University Hospital, Oulu, Finland

* Corresponding author: Kirsi Sipilä, Research Unit of Oral Health Sciences, University of Oulu, Finland, Box 5281, FIN-90014 Oulu, Finland, e-mail kirsi.sipila@oulu.fi 


\section{Role of Psychosocial Factors on Treatment Outcome of Temporomandibular Disorders}

Objectives: The aim of this randomized controlled study was to investigate the effect of depressive and non-specific physical symptoms on treatment outcome of temporomandibular disorders (TMD).

Material and methods: Eighty TMD patients were randomly assigned to splint group (n=39) and control group $(n=41)$. The patients were classified in terms of depressive and non-specific physical symptoms as normal, moderate or severe using Research Diagnostic Criteria for Temporomandibular Disorders Axis II protocol. The effect of depressive and non-specific physical symptoms on the intensity of facial pain, as measured with visual analogue scale (VAS) was estimated with linear mixed models. The patients' subjective estimates of the effects of treatment and TMD symptom severity were inquired at one-year follow-up.

Results: At baseline and during the follow-up there were no significant differences in VAS scores between patients in different Axis II subscales. According to the mixed linear regression, depressiveness or nonspecific physical symptoms separately were not significantly associated with the VAS during the study. The association of VAS with depressive $(\mathrm{p}=.073)$ and nonspecific physical symptoms ( $\mathrm{p}=.088)$ approximated statistical significance. Patients with moderate or severe nonspecific physical symptoms (with pain items) at baseline had more frequently moderate, severe or intolerable TMD symptoms after the treatment compared to those who were classified in normal subgroup.

Conclusions: The present study gave some indication of a possible negative effect of depressive and nonspecific physical symptoms (with pain items) on TMD treatment response. 
However, the results should be regarded as preliminary, and further studies with larger sample size are needed to confirm the results.

Keywords: clinical trial; orofacial pain; psychosocial factors; temporomandibular disorders; treatment

\section{Introduction}

Temporomandibular disorders (TMD) is a collective term that includes problems in masticatory muscles and/or temporomandibular joints (TMJ) and associated structures [1]. The most common TMD signs and symptoms are facial pain, deviations of mandibular movements, limited range of jaw movements, and TMJ sounds (crepitus, clicking). In the Finnish adult population the prevalence of having at least one TMD sign is thirty-eight percent, the signs being more common among women than men [2].

The etiology of TMD is considered multifactorial and the term biopsychosocial has been used to describe the complex nature of TMD [3]. Psychological and psychosocial problems, such as somatization and depression, have been reported to associate with TMD [3-9]. Depression and somatization, or "non-specific physical symptoms", are common among TMD patients; according to studies, 39-75\% of TMD patients are depressive and 48-77\% have non-specific physical symptoms $[8,9,10,11]$. Moreover, the incidence of TMD is higher among depressive persons than among non-depressive [12].

Typical treatment modalities for TMD are information and counseling, occlusal splint therapy, masticatory muscle exercises, physical therapy and medication [1]. Stabilization splint is the most common occlusal splint used in the treatment of TMD [1]. Although promising results have been reported with stabilization splint therapy, the results are still controversial [13-15]. The heterogeneity of the patient material and the possible role of psychological factors should be taken 
into account in the treatment [3]. Namely, some studies have shown that psychosocial factors and widespread pain may impair the response to conservative treatment of TMD $[16,17]$ and increase the risk for chronicity [4]. The Research Diagnostic Criteria (RDC/TMD) Axis II instruments have shown a good reliability and validity for evaluating the psychosocial factors in the background of TMD [18], and their use can contribute to successful clinical decision-making for the management of TMD [19]. The role of psychosocial factors in TMD treatment response has been investigated in a relatively short time interval [20]. The number of studies concerning the effect of psychosocial factors using valid criteria in their assessment on the TMD treatment outcome is scarce. Additional long-term follow-up studies are therefore needed to investigate the role of depressiveness and nonspecific physical symptoms on TMD treatment response.

Earlier, a randomized controlled clinical trial was conducted where the authors found that stabilization splint treatment showed no additional benefit as compared to masticatory muscle exercises alone during a one-year follow-up from a sample of 80 TMD patients [21]. However, the effect of psychosocial factors on the treatment outcome remained unclear.

The aim of this randomized controlled study was to investigate the effect of depressiveness and non-specific physical symptoms, based on the RDC/TMD Axis II criteria, on TMD treatment response in patients treated with stabilization splint compared to those performing only masticatory muscle exercises.

\section{Material and methods}

\section{Subjects}

The study sample consisted of 80 consecutive patients (18 men, 62 women) who had been referred to the Oral and Maxillofacial Department, Oulu University Hospital, Finland, for diagnosis and 
treatment of TMD from March 2008 to September 2009 and gave their written informed consent. The inclusion criteria for the study were 1) clinically diagnosed TMD as defined by the Research Diagnostic Criteria for Temporomandibular Disorders (RDC/TMD) [22], 2) at least 20 years of age, and 3) lack of any diagnosed general diseases that may affect TMJs or masticatory muscles.

Patients were randomly assigned by computer into two groups: splint and control group. One of the authors (KS) generated the random allocation sequence and assigned participants to interventions. Patients in the splint group $(n=39)$ were treated with a stabilization splint, counseling and masticatory muscle exercises. Patients in the control group $(n=41)$ received counseling and instructions for masticatory muscle exercises. The mean age of the patients was 43.2 years (SD 13.3 years) in the splint group and 44.0 years (SD 13.1 years) in the control group. The splint group consisted of 32 women/7 men and the control group of 30 women/11 men. The size of the sample was calculated with power analysis based on the data of an earlier study [23]. Differences in total score of Helkimo's clinical dysfunction index with a mean of 2 points (SD 3.5) between the groups can be achieved with $80 \%$ power (statistical significance $\mathrm{p}<0.05$, using t-test) with the sample size of 39 per group.

A clinical stomatognathic examination was performed at baseline according to the RDC/TMD criteria [22] by a dentist specialized in stomatognathic physiology (KS). The distribution of diagnostic subgroups of TMD among the patients has been presented in the earlier study [15]. The majority of the patients (97.3\% in the splint group, $82.9 \%$ in the control group) had myofascial pain diagnosis, the proportion of other diagnoses being lower.

\section{Data collection}

The same dentist (KS) conducted all of the follow-up examinations, being unaware of the group status of the patients. Anamnestic data were collected from both groups at the baseline (before treatment) of the study, and the intensity of facial pain was measured with a visual analogue scale 
(VAS) on a 0 (no pain) to 10 (pain as bad as could be) rating scale. Depressive and non-specific physical symptoms (with pain items excluded or included) scores were estimated at baseline with Axis II questionnaire included in the Finnish version of RDC/TMD [22,24]. Patients were further classified in terms of depressive and non-specific physical symptoms as normal, moderate, or severe, based on the reference values as suggested by Dworkin and LeResche [22].

In the follow-ups (after treatment), the patients' subjective estimates of the effects of treatment were evaluated with a questionnaire using a scale from 1 to 4 (1= "very good effect", $2=$ "treatment has helped to some extent", 3= "no difference / cannot tell" and 4= "symptoms worsened"). Additionally, TMD symptoms after treatment were also inquired with the following options: "no/not significant", “mild”, “moderate", "severe” and "intolerable”. Data collections (VAS on pain intensity, subjective estimate of treatment response and subjective estimate of TMD symptoms) were performed for both groups one, three, six and twelve months after the beginning of the study.

\section{Treatment procedures}

After baseline clinical examination, the stabilization splints were made of heat-cured acrylic by the same dental technician. The occlusion of the splint was defined in the centric relation occlusion using wax (Astynax, Associated Dental Products Ltd, UK). The occlusion of the splints was rechecked at follow-up visits.

The patients were instructed to perform a standardized program for masticatory muscle exercises as described by Carlsson and Magnusson [25]. At the beginning of the training program active mouth openings, laterotrusive movements and protrusive movements were performed. The mandible was held in the maximal positions for a few seconds on each movement. Thereafter, these movements were made towards resistance (using the patient's own fingers). After jaw exercises the patients were suggested to open the jaw wide, stretching it with fingers a few times for 10 to 20 seconds. These movements were repeated 7 to 10 times per training session, and the sessions were 
performed 2-3 times per day. The patients received written instructions, and the movements were also demonstrated by the dentist before the treatment, and reprised if necessary. The instructions for masticatory muscle exercises were given by the same dentist (KS) at the first visit. The stabilization splint treatments were performed by two other dentists who were carefully instructed in the treatment method.

\section{Attrition}

Thirty-one patients dropped out of the trial due to non-attendance of the check-ups and, or due to other treatments. Fourteen controls were treated with splint because of their symptoms and need of treatment and were excluded from the group. Fifteen patients (10 patients in the splint group and 5 in the control group) were treated with arthrocentesis of the TMJ during the study, this treatment did not fulfil the criteria for exclusion.

This study was approved by the ethical committee of Oulu University Hospital.

\section{Statistical analyses}

The mean VAS scores at baseline and during follow-ups were compared between patients with and without depressive or non-specific physical symptoms using one-way ANOVA test. The associations of patients' subjective assessment of the post-treatment TMD symptoms and treatment outcome (at one-year follow-up) with Axis II subscales were estimated using $\chi 2$ test. The association of depressive or non-specific physical symptoms (using both as classified based on 3 subclasses and as continuous variable calculated from total scores) with the VAS was estimated with mixed linear regression, which took into account treatment time (1, 3, 6 and 12 months), age, gender, and treatment group (splint versus control group). Analyses were performed using IBM statistics SPSS software version 19.0. 


\section{Results}

At the beginning of the study, the percentages for normal, moderate and severe depressive symptoms were $53.8,27.5$ and $15.0 \%$, respectively. The corresponding percentages were $42.5,30.0$ and $22.5 \%$ for non-specific physical symptoms with pain items excluded and 32.5, 36.3 and $27.5 \%$ for non-specific physical symptoms with pain items included. There were no significant differences in mean age or distributions of gender or Axis II subscales between the treatment groups (splint vs. control) (Table 1).

[Table 1 near here]

At baseline the mean score and standard deviation (SD) of VAS on facial pain intensity was 5.1 (SD 2.8) in the splint group and 4.6 (SD 2.6) in the control group, the difference being insignificant. At baseline and during the follow-ups there were no significant differences in mean scores of VAS on facial pain intensity between patients in different Axis II subscales (Table 2). The mean of VAS score was the lowest at the six-month follow-up in most of the Axis II subscales, except in severe depression and moderate non-specific physical symptoms (with pain items excluded) subscales, where the VAS scores fluctuated more during the follow-up (Table 2).

[Table 2 near here]

At one-year follow-up, there were no significant differences between patients' subjective estimates of the effects of treatment or TMD symptoms after treatment and most of the Axis II subscale profiles (Table 3). Patients with moderate or severe nonspecific physical symptoms (with pain items included) had more frequently moderate, severe or intolerable symptoms after the treatment compared to those who were classified in the normal subgroup $(\mathrm{p}=0.048$ ) (Table 3 ). 
According to the linear regression, depressive or nonspecific physical symptoms separately were not significantly associated with VAS during the study (Table 4, models 1-3). The association of VAS with depressive $(\mathrm{p}=.073)$ and nonspecific physical symptoms $(\mathrm{p}=.088)$ approximated statistical significance. The presence of nonspecific physical symptoms with pain items excluded correlated highly with the nonspecific physical symptoms with pain items included $(c=0.830$, Spearman). Therefore depressive and nonspecific physical symptoms were at first included separately in the mixed models and only finally all three together. When depressive and nonspecific physical symptoms (with pain items excluded or included) together were taken into account in the mixed model, their association with VAS was not significant (Table 4, model 4).

[Table 4 near here]

When using Axis II subscales as a continuous variable in the linear regression, their associations with VAS were not significant.

\section{Discussion}

The results of the present study gave some indication that subjects with depressive and nonspecific physical symptoms (linked with pain symptoms) showed poorer treatment response of TMD, compared to those without these symptoms, during a one-year follow-up, despite the treatment method offered. Although the associations of these psychosocial variables with the intensity of facial pain were not significant, some tendency for the negative effect of these variables was shown. Moreover, based on the patient's subjective estimate, moderate or severe nonspecific physical symptoms (with pain items included) at baseline associated with severe symptoms after treatment, which may partly support the results. The treatment time seems to be associated with VAS decrease, the six-month follow-up showing the lowest values.

The present study gives new information on the association of psychosocial problems with TMD treatment response, as there exist only few studies concerning the topic. A recent study by 
Litt and Porto [16] from 101 subjects with chronic TMD indicated that treatment non-responders accounted for $16 \%$ of the sample and they reported more psychiatric symptoms, poorer coping, and higher levels of catastrophizing. Earlier, Raphael and Marbach [17] found in their randomized, controlled clinical trial from 63 women with myofascial face pain that patients with widespread pain who received an active splint did not experience improvement, while patients with local pain who received the active splint did, based on six-week follow-up. These results along with the present findings suggest that general risk factors related to pain chronicity may have an impairing effect on TMD treatment outcome and thus should be considered in treatment planning.

The present study group comprised more myogenous than arthrogenous patients, of which the former subgroup has shown to be more linked with depressive and non-specific physical symptoms [26]. In the present study, nonspecific physical symptoms linked with pain symptoms had some tendency for an impaired treatment outcome. Studies have shown that somatic awareness and somatization are highly associated with widespread pain and the number of muscle sites painful to palpation [27], chronic myofascial pain [28] and persistent TMD pain [7], thus supporting our results. Somatization may be linked with pain beliefs, which have been shown to be important predictors of treatment outcome and should be considered in the management of TMD patients [29]. Somatizing patients may also be more vulnerable to report symptoms, including facial pain intensity, which may also explain the present findings.

The present study showed that depressive and nonspecific physical symptoms seem to be relatively common among TMD patients, especially tertiary care patients. The study population consisted of special health care patients who had suffered from chronic and severe TMD. At baseline approximately half of the patients were classified in the moderate or severe subscales of depressive or nonspecific physical symptoms. These results are in accordance with previous studies [8-11]. 
In the present study the treatment time showed significant association with facial pain intensity. The mean of VAS score was the lowest at the six-month follow-up in most of the Axis II subscales, except in severe depression and moderate non-specific physical symptoms (with pain items excluded) subscales, where the VAS scores fluctuated more during the follow-up. The decrease in VAS may partly be explained by normal fluctuation of TMD symptoms, which may be effected by the psychosocial factors. It should be noted that during the first six months control visits were frequent, while during the last six months there were no control visits except for the last control (after 12 months). Fewer control visits and thus less contact with the doctor during the last half-year period may have an effect on the symptom report.

The outcome of the treatment was measured using several patients' subjective estimates, which can be considered one of the strengths of the study. Moreover, the RDC/TMD Axis II instruments used in the present study have shown to be reliable and valid for measuring psychosocial status $[30,31]$. The randomized control study design and a relatively long follow-up period were also strengths of the study. One limitation of the study was a relatively small sample size, which is why the number of patients in separate Axis II subscales remained relatively low and may thus have weakened the statistical power. Therefore, the results should be regarded only as indicative, and further studies with larger samples are needed to confirm the present findings. Additionally, attrition caused restrictions in the study. In the case of severe symptoms, other treatments were offered and the original group status changed in some cases. Therefore, the time the patients had remained in their original groups was included in the follow-up and taken into account in the analysis. One limitation of the study was related to the additional treatments; 15 patients received TMJ arthrocentesis. Those patients were not excluded from the study (unlike the patients in the control group who received splint treatment), because the original study design was based on splint vs. control treatment, not the arthrocentesis treatment. Further, it should be noted that the aim 
here was primarily to investigate the role of psychosocial factors on treatment response, and not merely the effect of distinct treatment methods, which has been reported in the earlier study [21].

The present study gave some indication of a possible negative effect of depressive and nonspecific physical symptoms on the treatment response of TMD during a one-year follow-up. However, the results should be regarded as preliminary, and further studies with more homogenous materials and larger sample sizes are needed to support or to oppose the present suggestive results. Patients suffering from psychological and psychosocial problems have been shown to benefit from multidisciplinary treatment [3]. Recent studies have indicated that individualized TMD treatment that takes psychosocial factors into consideration should be offered, and rehabilitation rather than cure is preferred for the treatment of complex and chronic TMD conditions $[7,10,32]$. The present study investigated the effect of psychosocial factors on conservative TMD treatment. In the future, however, additional studies on more customized treatments of TMD based on the patient's psychosocial status are warranted.

Based on the present study it can be concluded that depressive and nonspecific physical symptoms are relatively common among TMD patients. The results gave some indication of a possible negative effect of psychosocial factors on the TMD treatment outcome. The sample size in the present study was quite small, and therefore the results can only be regarded as indicative. Further investigations are needed to clarify the effect of psychosocial factors on the outcome of TMD treatment.

\section{Acknowledgements}

Conflicts of interest: No conflicts of interest are declared.

This research was funded by the Academy of Finland and the Finnish Dental Society Apollonia. 


\section{References}

[1] Okeson JP. 2013. Management of temporomandibular disorders and occlusion. $7^{\text {th }}$ edition. St Louis, Missouri: Mosby.

[2] Rutkiewicz T, Könönen M, Suominen-Taipale L, Nordblad A, Alanen P. Occurence of clinical signs of temporomandibular disorders in adult Finns. J Orofac Pain. 2006;20:208-217.

[3] Suvinen TI, Reade PC, Kemppainen P, Könönen M, Dworkin SF. Review of aetiological concepts of temporomandibular pain disorders: towards a biopsychosocial model for integration of physical disorder factors with psychological and psychosocial illness impact factors. Eur J Pain. 2005;9:613-633.

[4] Fillingim RB, Ohrbach R, Greenspan JD, Knott C, Diatchenko L, Dubner R, Bair E, Baraian C, Mack N, Slade GD, Maixner W. Psychological factors associated with development of TMD: the OPPERA prospective cohort study. J Pain. 2013;14 Suppl:75-90.

[5] Guarda-Nardini L, Pavan C, Arveda N, Ferronato G, Mafredini D. Psychometric features of temporomandibular disorders patients in relation to pain diffusion. J Oral Rehabil. 2012;39:737743.

[6] Sipilä K, Mäki P, Laajala A, Taanila A, Joukamaa M, Veijola J. Association of depressiveness with chronic facial pain - a longitudinal study. Acta Odontol Scand. 2013;71:644-649.

[7] Velly AM, Look JO, Carlson C, Lenton PA, Kang W, Holcroft CA, Fricton JR. The effect of catastrophizing and depression on chronic pain--a prospective cohort study of temporomandibular muscle and joint pain disorders. Pain. 2011;152:2377-2383. 
[8] Yap AUJ, Tan KBC, Chua EK, Tan HH. Depression and somatization in patients with temporomandibular disorders. J Prosthet Dent. 2002;88:479-484.

[9] Yap AUJ, Dworkin SF, Chua EK, List T, Tan KBC, Tan HH. Prevalence of temporomandibular disorder subtypes, psychologic distress, and psychosocial dysfunction in Asian patients. J Orofac Pain. 2003;17:21-28.

[10] Manfrenidi D, Borella L, Favero L, Ferronato G, Guarna-Nardini L. Chronic pain severity and depression/somatization levels in TMD patients. Int J Prosthodont. 2010;23:529-534.

[11] Manfrenidi D, Arveda N, Guarda-Nardini L, Segu M, Collesano V. Distribution of diagnoses in a population of patients with temporomandibular disorders. Surg Oral Med Oral Pathol Oral Radiol. 2012;114:35-41.

[12] Liao CH, Chang CS, Chang SN, Lane HY, Lyu SY, Morisky DE, Sung FC. The risk of temporomandibular disorder in patients with depression: a population-based cohort study. Community Dent Oral Epidemiol. 2011;39:525-531.

[13] Al-Ani Z, Gray RJ, Davies SJ, Sloan P, Glenny AM. Stabilization splint therapy for the treatment of temporomandibular myofascial pain: a systematic review. J Dent Educ. 2005;69:12421250.

[14] Michelotti A, Iodice G, Vollaro S, Steenks MH, Farella M. Evaluation of the short-term effectiveness of education versus an occlusal splint for the treatment of myofascial pain of the jaw muscles. J Am Dent Assoc. 2012;143:47-53.

[15] Niemelä K, Korpela M, Raustia A, Ylöstalo P, Sipilä K. Efficacy of stabilization splint treatment on temporomandibular disorders. J Oral Rehabil. 2012;39:799-804. 
[16] Litt MD, Porto FB. Determinants of pain treatment response and nonresponse: identification of TMD patient subgroups. J Pain. 2013;14:1502-1513.

[17] Raphael KG, Marbach JJ. Widespread pain and the effectiveness of oral splints in myofascial face pain. J Am Dent Assoc. 2001;132:305-316.

[18] Dworkin SF, Sherman J, Mancl L, Ohrbach R, LeResche L, Truelove E. Reliability, validity, and clinical utility of the Research Diagnostic Criteria for Temporomandibular Disorders Axis II scales: Depression, non-specific physical symptoms, and graded chronic pain. J Orofac Pain 2002;16:207-220.

[19] Dworkin SF, Huggins KH, Wilson L, Mancl L, Turner J, Massoth D, LeResche L, Truelove E A randomized clinical trial using research diagnostic criteria for temporomandibular disorders-axis II to target clinic cases for a tailored self-care TMD treatment program. J Orofac Pain. 2002:16:4863.

[20] Nilsson H, Ekberg E. Do psychological factors and general health influence the short-term efficacy of resilient appliance therapy in patients with temporomandibular disorder pain? Acta Odontol Scand. 2010;68:141-147.

[21] Qvintus V, Suominen AL, Huttunen J, Raustia A, Ylöstalo P, Sipilä K. Efficacy of stabilisation splint treatment on facial pain - 1-year follow-up. J Oral Rehabil. 2015; 42:439-446.

[22] Dworkin SF, LeResche L. Research diagnostic criteria for temporomandibular disorders: Review, criteria, examinations and specifications, critique. J Craniomandib Disord. 1992;6:301355.

[23] Sipilä K, Zitting P, Siira P, Laukkanen P, Järvelin MR, Oikarinen KS, Raustia AM.

Temporomandibular disorders, occlusion, and neck pain in subjects with facial pain: a case-control study. Cranio. 2002;20:158-64. 
[24] Suvinen T, Rantala M, Ahlberg J, Könönen M. RDCTMD_FIN.2010 www.rdctmdinternational.org.

[25] Carlsson GE, Magnusson T. 1999. Treatment modalities. In: Bywaters LC, editor.

Management of temporomandibular disorders in the general dental practice. Chicago: Quintessence. p. 93-103.

[26] Park JW, Clark GT, Kim YK, Chung JW. Analysis of thermal pain sensitivity and psychological profiles in different subgroups of TMD patients. Int J Oral Maxillofac Surg. 2010; 39:968-974.

[27] Yap AU, Chua EK, Tan KB, Chan YH. Relationships between depression/somatization and self-reports of pain and disability. J Orofac Pain. 2004;18:220-225.

[28] Rantala MA, Ahlberg J, Suvinen TI, Savolainen A, Könönen M. Chronic myofascial pain, disk dis-placement with reduction and psychosocial factors in Finnish non-patients. Acta Odontol Scand. 2004; 62:293-297.

[29] Galli U, Ettlin DA, Palla S, Ehlert U, Gaab J. Do illness perceptions predict pain-related disability and mood in chronic orofacial pain patients? A 6-month follow-up study. Eur J Pain. 2010;14:550-558.

[30] Dworkin SF, Sherman J, Mancl L, Ohrbach R, LeResche L,Truelove E. Reliability, validity, and clinical utility of the Research Diagnostic Criteria for Temporomandibular Disorders Axis II scales: Depression, non-specific physical symptoms, and graded chronic pain. J Orofac Pain. 2002;16:207-220.

[31] Ohrbach R, Turner JA, Sherman JJ, Mancl LA, Truelove EL, Schiffman EL. The Research Diagnostic Criteria for Temporomandibular Disorders: IV: Evaluation of psychometric properties of the Axis II measures. J Orofac Pain. 2010; 24:48-62. 
[32] Kotiranta U, Suvinen T, Forssell H. Tailored treatments in temporomandibular disorders:

where are we now? A systematic qualitative literature review. J Oral Facial Pain Headache. 2014;

28:28-37. 
Table 1. Baseline data of patients with temporomandibular disorders, assigned randomly to splint and control groups. Depressive and non-specific physical symptoms were defined based on Research Diagnostic Criteria for Temporomandibular Disorders (RDC/TMD) Axis II subscales $[22]$.

\begin{tabular}{|c|c|c|c|c|c|}
\hline & \multicolumn{2}{|c|}{ Splint group } & \multicolumn{2}{|c|}{ Control group } & \multirow[t]{2}{*}{$\mathrm{p}^{*}$} \\
\hline & $\mathrm{n}$ & $\begin{array}{l}\text { mean } \\
\text { (SD) }\end{array}$ & $n$ & $\begin{array}{l}\text { mean } \\
(\mathrm{SD})\end{array}$ & \\
\hline Age/years & 39 & \begin{tabular}{|l|}
43.2 \\
$(13.3)$
\end{tabular} & 41 & $\begin{array}{l}44.0 \\
(13.1)\end{array}$ & .776 \\
\hline & $\mathrm{n}$ & $\%$ & $\mathrm{n}$ & $\%$ & \\
\hline $\begin{array}{c}\text { Gender } \\
\text { Female } \\
\text { Male } \\
\end{array}$ & $\begin{array}{l}32 \\
7 \\
\end{array}$ & \begin{tabular}{|l|}
82.1 \\
17.9 \\
\end{tabular} & $\begin{array}{l}30 \\
11 \\
\end{array}$ & \begin{tabular}{|l|}
73.2 \\
26.8 \\
\end{tabular} & .342 \\
\hline $\begin{array}{l}\text { Depressive symptoms } \\
\quad \text { Normal } \\
\text { Moderate } \\
\text { Severe } \\
\end{array}$ & $\begin{array}{l}23 \\
12 \\
3 \\
\end{array}$ & $\begin{array}{l}60.5 \\
31.6 \\
7.9 \\
\end{array}$ & $\begin{array}{l}20 \\
10 \\
9\end{array}$ & \begin{tabular}{|l|}
51.3 \\
25.6 \\
23.1 \\
\end{tabular} & .185 \\
\hline $\begin{array}{l}\text { Nonspecific physical symptoms (pain items excl.) } \\
\text { Normal } \\
\text { Moderate } \\
\text { Severe }\end{array}$ & $\begin{array}{l}20 \\
11 \\
6\end{array}$ & $\begin{array}{l}54.1 \\
29.7 \\
16.2\end{array}$ & $\begin{array}{l}14 \\
13 \\
12\end{array}$ & $\begin{array}{l}35.9 \\
33.3 \\
30.8\end{array}$ & 204 \\
\hline $\begin{array}{l}\text { Nonspecific physical symptoms (pain items incl.) } \\
\text { Normal } \\
\text { Moderate } \\
\text { Severe }\end{array}$ & $\begin{array}{l}16 \\
12 \\
10\end{array}$ & $\begin{array}{l}42.1 \\
31.6 \\
26.3\end{array}$ & $\begin{array}{l}10 \\
17 \\
12\end{array}$ & $\begin{array}{l}25.6 \\
43.6 \\
30.8\end{array}$ & \begin{tabular}{l|l|l}
.299 \\
\end{tabular} \\
\hline
\end{tabular}

$\mathrm{SD}=$ Standard deviation

$* \mathrm{Chi}^{2}$ test 
Table 2. The mean (SD, standard deviation) VAS (Visual Analogue Scale) values at the baseline and during follow-up according to the depressive and nonspecific physical symptoms (with pain items excluded or included). Depressive and nonspecific physical symptoms were defined based on Research Diagnostic Criteria for Temporomandibular Disorders (RDC/TMD) Axis II subscales $[22]$.

\begin{tabular}{|c|c|c|c|c|c|c|c|c|c|c|c|c|}
\hline & \multicolumn{4}{|c|}{ Depressive symptoms } & \multicolumn{4}{|c|}{$\begin{array}{l}\text { Non-specific physical } \\
\text { symptoms } \\
\text { (pain items excluded) }\end{array}$} & \multicolumn{4}{|c|}{$\begin{array}{l}\text { Non-specific physical } \\
\text { symptoms } \\
\text { (pain items included) }\end{array}$} \\
\hline & Normal & Moderate & Severe & $\mathrm{p}^{*}$ & Normal & Moderate & Severe & $\mathrm{p}$ & Normal & Moderate & Severe & $\mathrm{p}$ \\
\hline $\begin{array}{l}\text { Baseline } \\
(n=80)\end{array}$ & $\begin{array}{l}4.40 \\
(2.50)\end{array}$ & $\begin{array}{l}5.77 \\
(2.83)\end{array}$ & $\begin{array}{l}4.67 \\
(2.96)\end{array}$ & .147 & $\begin{array}{l}4.82 \\
(2.74)\end{array}$ & $\begin{array}{l}4.79 \\
(2.83)\end{array}$ & $\begin{array}{l}4.94 \\
(2.69)\end{array}$ & .983 & $\begin{array}{l}4.31 \\
(3.08)\end{array}$ & $\begin{array}{l}5.62 \\
(2.26)\end{array}$ & $\begin{array}{l}4.41 \\
(2.63)\end{array}$ & .136 \\
\hline $\begin{array}{l}1 \text { month } \\
(n=75)\end{array}$ & $\begin{array}{l}3.17 \\
(2.79)\end{array}$ & $\begin{array}{l}4.45 \\
(3.00)\end{array}$ & $\begin{array}{l}3.44 \\
(2.96)\end{array}$ & .244 & $\begin{array}{l}3.84 \\
(3.03)\end{array}$ & $\begin{array}{l}3.55 \\
(2.70)\end{array}$ & $\begin{array}{l}3.24 \\
(3.09)\end{array}$ & .785 & $\begin{array}{l}3.00 \\
(2.70)\end{array}$ & $\begin{array}{l}4.37 \\
(2.90)\end{array}$ & $\begin{array}{l}3.29 \\
(3.02)\end{array}$ & .205 \\
\hline $\begin{array}{l}3 \\
\text { months } \\
(n=51)\end{array}$ & $\begin{array}{l}2.89 \\
(2.36)\end{array}$ & $\begin{array}{l}4.13 \\
(2.68)\end{array}$ & $\begin{array}{l}3.60 \\
(3.05)\end{array}$ & .303 & $\begin{array}{l}3.09 \\
(2.66)\end{array}$ & $\begin{array}{l}3.73 \\
(2.34)\end{array}$ & $\begin{array}{l}3.45 \\
(2.73)\end{array}$ & .748 & $\begin{array}{l}2.29 \\
(2.59)\end{array}$ & $\begin{array}{l}3.94 \\
(2.05)\end{array}$ & $\begin{array}{l}3.93 \\
(2.76)\end{array}$ & .097 \\
\hline $\begin{array}{l}6 \\
\text { months } \\
(n=42)\end{array}$ & $\begin{array}{l}2.27 \\
(2.31)\end{array}$ & $\begin{array}{l}2.82 \\
(2.99)\end{array}$ & $\begin{array}{l}3.57 \\
(3.21)\end{array}$ & .524 & $\begin{array}{l}2.17 \\
(2,26)\end{array}$ & $\begin{array}{l}3.36 \\
(3.11)\end{array}$ & $\begin{array}{l}2.73 \\
(2.83)\end{array}$ & .506 & $\begin{array}{l}2.14 \\
(2.57)\end{array}$ & $\begin{array}{l}3.00 \\
(2.17)\end{array}$ & $\begin{array}{l}2.86 \\
(3.16)\end{array}$ & .205 \\
\hline $\begin{array}{l}12 \\
\text { months } \\
(\mathrm{n}=49)\end{array}$ & $\begin{array}{l}3.04 \\
(2.12)\end{array}$ & $\begin{array}{l}4.65 \\
(3.43)\end{array}$ & $\begin{array}{l}1.00 \\
(1.27)\end{array}$ & .014 & $\begin{array}{l}3.15 \\
(2.62)\end{array}$ & $\begin{array}{l}3.25 \\
(3.15)\end{array}$ & $\begin{array}{l}3.91 \\
(2.81)\end{array}$ & .765 & $\begin{array}{l}2.53 \\
(2.85)\end{array}$ & $\begin{array}{l}4.00 \\
(2.83)\end{array}$ & $\begin{array}{l}3.62 \\
(2.66)\end{array}$ & .296 \\
\hline
\end{tabular}

* based on ANOVA. 
Table 3. The association of the baseline depressive and nonspecific physical symptoms (with pain items excluded or included) with the patients'subjective assessment of the treatment outcome and the symptoms of temporomandibular disorders (TMD) one year after the treatment. Depressive and nonspecific physical symptoms were defined based on RDC/TMD Axis II subscales [22].

\begin{tabular}{|c|c|c|c|c|c|c|}
\hline & \multicolumn{2}{|c|}{ Treatment outcome } & \multicolumn{4}{|c|}{$\begin{array}{c}\text { TMD symptoms after } \\
\text { treatment }\end{array}$} \\
\hline & $\begin{array}{l}\text { very } \\
\text { good/ } \\
\text { helped to } \\
\text { some } \\
\text { extent } \\
\mathrm{n}(\%)\end{array}$ & $\begin{array}{l}\text { no } \\
\text { difference/ } \\
\text { worsened }\end{array}$ & $\mathrm{p}$-value & $\begin{array}{l}\text { no/no } \\
\text { spesific/mild }\end{array}$ & $\begin{array}{l}\text { moderate/severe/ } \\
\text { intolerable }\end{array}$ & $\mathrm{p}$-value \\
\hline \multicolumn{7}{|c|}{$\begin{array}{l}\text { Depressive } \\
\text { symptoms }\end{array}$} \\
\hline Normal & $21(58.3)$ & $10(43.5)$ & 0.222 & $19(57.6)$ & $12(46.2)$ & .193 \\
\hline Moderate & $8(22.2)$ & $10(43.5)$ & & $7(21.2)$ & $11(42.3)$ & \\
\hline Severe & $7(19.4)$ & $3(13.0)$ & & $7(21.2)$ & $3(11.5)$ & \\
\hline \multicolumn{7}{|c|}{$\begin{array}{l}\text { Nonspecific } \\
\text { physical } \\
\text { symptoms * }\end{array}$} \\
\hline Normal & $18(50.0)$ & $8(34.8)$ & 0.516 & $17(51.5)$ & $9(34.6)$ & .278 \\
\hline Moderate & $11(30.6)$ & $9(39.1)$ & & $11(33.3)$ & $9(34.6)$ & \\
\hline Severe & $7(19.4)$ & $6(26.1)$ & & $5(15.2)$ & $8(30.8)$ & \\
\hline \multicolumn{7}{|c|}{$\begin{array}{l}\text { Nonspecific } \\
\text { physical } \\
\text { symptoms } \\
* *\end{array}$} \\
\hline Normal & $15(41.7)$ & $5(21.7)$ & 0.221 & $15(45.5)$ & $5(19.2)$ & .048 \\
\hline Moderate & $14(38.9)$ & $10(43.5)$ & & $13(39.4)$ & $11(42.3)$ & \\
\hline Severe & $7(19.4)$ & $8(34.8)$ & & $5(15.2)$ & $10(38.5)$ & \\
\hline
\end{tabular}

*pain items excluded, **pain items included 
Table 4. The effect of explanatory variables on the intensity of facial pain (VAS) as estimated with linear regression model. Depressive and nonspecific physical symptoms were defined based on Research Diagnostic Criteria for Temporomandibular Disorders (RDC/TMD) Axis II subscales [22].

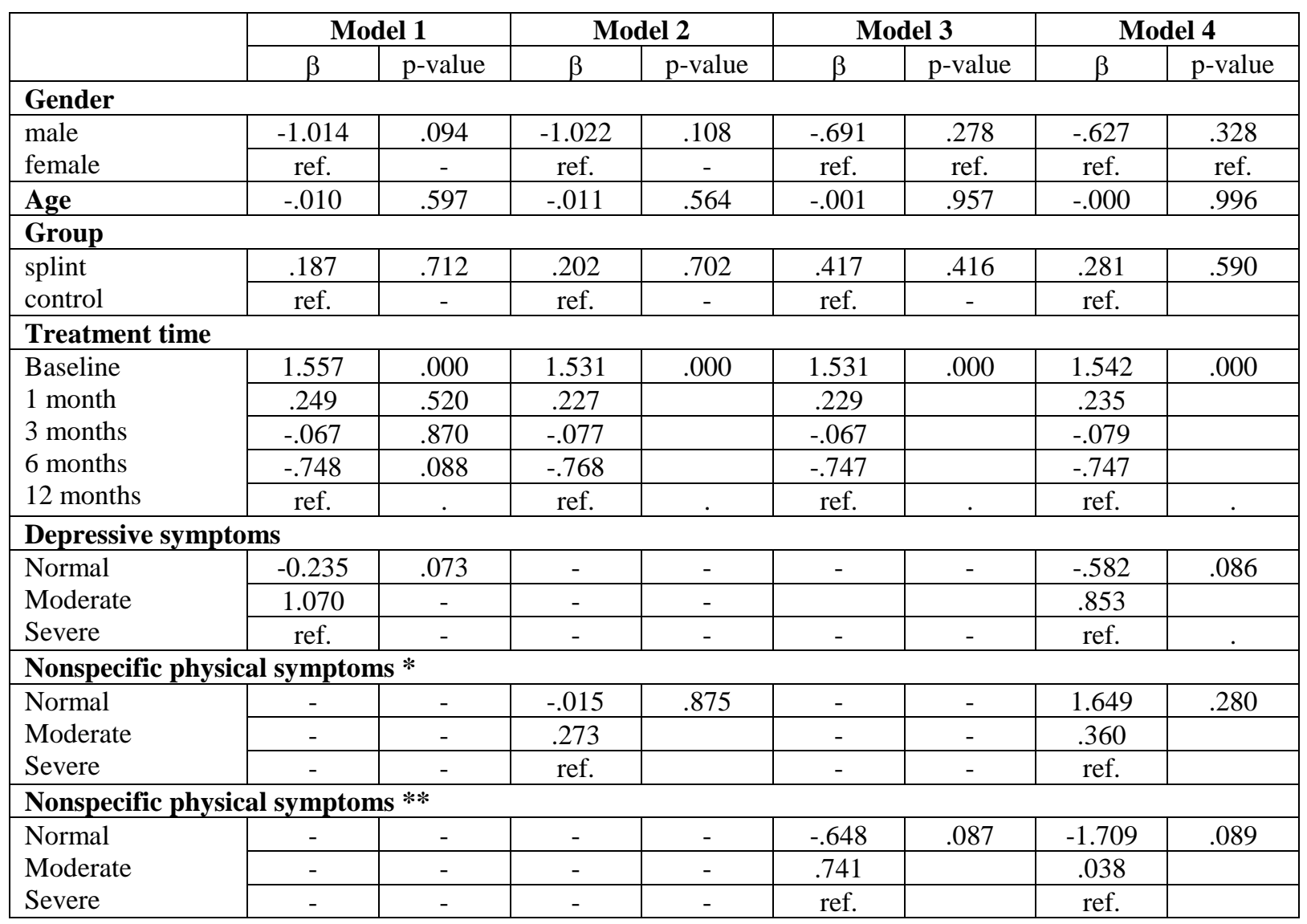

* pain items excluded, ** pain items included 
Figure legends

Figure 1. Flow chart of the study subjects. 